\title{
Autorstvo »Paše duhovne«
}

Knezović Pavao*

pknezovic@gmail.com https://doi.org/10.31192/np.16.3.4

UDK: 27-789.32Barišić, R.

82-141: 82.09

Izvorni znanstveni rad / Original scientific paper

Primljeno: 13. lipnja 2018.

Prihvaćeno: 6. rujna 2018.

Biskup fra Rafo Barišić, dok se nalazio u Rimu zbog spora s upravom provincije Bosne srebrene, sakupio je nekoliko knjižica na talijanskom i latinskom jeziku (prvenstveno onih koje donose molitve za čije su moljenje razne oproste dali pojedini pape) i, uz pomoć svoga tajnika fra Marka Kalamuta, sastavio je molitvenu knjigu nazvanu »Paša duhovna" (Rim, 1842.) koju je narod jednostavno nazivao »Biskupova knjiga«. U njezinu predgovoru (str. 5-15) Barišić je obradio gotovo potpun program ilirskog preporoda. Međutim, u ovom se radu nastoji pružiti suvisao odgovor zbog čega se u svim biografijama »Pašu duhovnu «navodi među Barišićevim glavnim djelima, iako neki navode da je to prijevod. Međutim, samo desetak što kraćih, što dužih pjesama, oko 640 stihova, jest ispjevao fra Rafo Barišić. Učinio je to jer je znao da se njegovu puku sviđaju stihovi pa se i on okušao u stvaranju sakralne poezije. K tome treba imati na umu da svatko tko je znao čitati, morao je to činiti naglas da bi i neuki puk naučio što se nalazi u »Biskupovoj knjizi«. Svakako da su za recitiranje prikladniji stihovi nego proza. Barišić je bio slab pjesnik $i$ čini se da je svu snagu "potrošio" na stvaranje rime (koja je posvuda pravilna) i teološki ispravnog sadržaja. Ipak treba reći da se u tim Barišićevim osmeračkim pjesmama nalaze mnogi veoma dobri distisi.

Ključne riječi: Fra Rafo Barišić, »Paša duhovna«, Barišićeve pjesme, savršena rima i teološka točnost.

\footnotetext{
* Prof. dr. sc. Pavao Knezović, Hrvatski studiji, Sveučilište u Zagrebu, Borongajska cesta 83d, HR-10000 Zagreb.
} 
Brojni, uglavnom kraći, životopisi biskupa i prvog hercegovačkog apostolskoga vikara fra Rafe Barišića napisani su i tiskani povodom njegove smrti 1863. godine. ${ }^{1} \mathrm{U}$ njima je redovito opisano biskupovo djelovanje, koje je veoma obilovalo turbulentnim događajima, ${ }^{2}$ ali se toga segmenta ne dotiče ovaj rad. Biografije tiskane povodom biskupove smrti redovito su ukratko opisivale biskupov život s posebnim osvrtom na njegovu golemu angažiranost u crkvenim poslovima i odnosima s turskim vlastima, dok su od pisanih djela uglavnom navodili naslove i/ili koju kraću opasku o samom djelu. Najvjerojatnije je najmanje podataka o njegovu životu i djelima donio fra Ivan Franjo Jukić, koji ga još za života spominje u drugom broju Bosanskog prijatelja (1851.), što je veoma značajno jer baca sasvim novo svjetlo na narodni preporod u Bosni i Hercegovini - nedvojbeno je Jukić znao tko je Barišić i što je napisao u predgovoru »Paše duhovne« (1842.), pa ipak u biografiji o Barišićevu životu donosi minimum podataka, ${ }^{3}$ dok o njegovu opusu navodi: »Štampao je 〈Paša duhovna' itd. u Rimu 1842. u 8. str. 439. - Preštampao je Bandulavića Pištole i Evangjelja u Rimu 1840. od slova do slova, kao što je izdanje Petra Kneževića. « ${ }^{4}$ Međutim već o. Jako Matković je znatno opširniji, ${ }^{5}$ a »Pašu duhovnu« stavlja na prvo mjesto: »Njegov književni rad ovaj je: a) 'Paša duhovna iliti način vješt slišati sv. misu’ (prev. s tal. i lat.) Rim. prop. 1842., 12., str. 439.« ${ }^{6}$ Biskupov tajnik napisao

${ }^{1}$ Usp. Anto Slavko KOVAČIĆ, Barišić, Rafo ml., u: Biobibliografija franjevaca Bosne Srebrene, Sarajevo, Svjetlost - Narodna i univerzitetska biblioteka BiH, 1991, 59-64.

${ }^{2}$ Najcjelovitiji i veoma neutralan, a tim i najbliži istini, tekst o životu apostolskog vikara narisao je fra Radoslav Glavaš u monografiji: Život i rad fra Rafe Barišića naslovnog biskupa azotskoga i apostolskog namjesnika u Bosni i Hercegovini, Mostar, Hrvatska dionička tiskara, 1900.

3 »Biskup Azotski, namiesnik apostolski odprie u svoj Bosni, a sada u Hercegovini« (Ivan Franjo JUKIĆ, 12. Rafo Barišić, Bosanski prijatelj - časopis sadéržavajući potrebite, koristne i zabavne stvari, (ur. I. F. Jukić Banjalučanin), sv. 2., Zagreb, Bèrzotiskom dra Ljudevita Gaja, 1851, 89).

${ }^{4}$ Isto.

${ }^{5}$ »Barišić o. Rafo, rodjen je u Oćeviji 29. lipnja 1797., stupio u franjevački red 16. travnja 1817., više je nauke svršio u Torinu u Italiji, gdje je položio stroge izpite iz filozofije i bogoslovije. Kroz njeko vrieme predavao je bogosloviju. God. 1830. naimenovan je župnikom u Zoviku. God. 1832. bude naimenovan biskupom azotskim i namjesnikom apostolskim u Bosni. God. 1846. naimenovan je vikarom apostolskim samo za Hercegovinu i pridje u Mostar, te je u Hercegovini ostao sve do smrti 14. kolovoza 1863. Umro je na Širokom-brigu. Bio je jako učevan i pametan, te je radi svojih inih vrlina bio odlikovan od turskog cara i od cesara austrijskoga Franje I. Negov književni rad ovaj je: $a$ ) Paša duhovna iliti način vješt slišati sv. misu (prev. s tal. i lat.) Rim. prop. 1842., 12., str. 439. b) Pištole i Evangjelja od Bandulovića i Knezovića jedini dao preštampati u Rimu. c) Conclusiones ex universa philosophia selectae quas publico exhibet examini etc. Taurini 1821., vel. 8., str. 21. d) Theses ex theologia selectae. Taurini 1822., 8. vel., str. 56. e) Obrana pravovjernoga ili pravoslavnoga svećenstva i naroda u Hercegovini turskoj proti potvoram i lažima koje im se nabacuju u Magazinu serbsko dalmatinskom izdatu 1851. U Dubrovniku 1853. - (Opazka. Ovu knjigu po naputku biskupa Barišića napisao je o. Marko Kalamut, onovremeni njegov tajnik, kao što je ovaj sam više put pred mnogima za života svoga kazivao.) U rukopisu je ostavio sliedeća djela: a) 'Marijin mjesec', b) 'Filotea, c) 'Kršćanska razmatranja' u četiri sveska, $d$ ) 'Tumačenje evangjelja za sve nedjelje u godini' od Ivana Craseta« (Jako MATKOVIĆ, Barišić o. Rafo, u: Bibliografija bosanskih franjevaca - tiskane knjige, Sarajevo, Zemaljska štamparija, 1896, 16-17).

${ }^{6}$ Isto, 17. 
je poprilično opširan životopis u Zagrebačkom katoličkom listu i pored ostaloga navodi: »Tiskom izdade navlastito za last i prud svog ljubljenog stada knjigu s naslovom 'Paša duhovna'."

Fra Radoslav Glavaš u biografiji tiskanoj $\mathrm{u} »$ Spomenici pedesetgodišnjice Hercegovačke franjevačke redodržave" sasvim šturo donosi: »Dok je bio Barišić u Rimu napisa liepu i kod našega naroda obljubljenu molitvenu knjigu 'Paša duhovna'. ${ }^{8}$ Pored Kalamuta Glavaš navodi da je taj molitvenik bio obljubljen u Hercegovini. Međutim Glavaševa karakteristika da je »Paša duhovna« bila obljubljena »kod našega naroda« ne podrazumijeva samo Hercegovinu nego sav hrvatski puk. Pišući o bogoslovnom radu Jelenić od Barišićevih djela spominje: »Theses ex theologia selectae, Taurini, 1822.«, ${ }^{9}$ a spominje također da je »biskupa Barišića 'Paša duhovna iliti način vješt slišati sv. misu' [tiskana] (Rim, 1842. $\ll .^{10}$ Alilović navodi samo naslov »Paša duhovna, Rim, $1842 .{ }^{11}{ }^{11} \mathrm{~Pa}$ i na službenim stranicama podaci govore da je pisac veoma malo znao o tom Barišićevu djelu. ${ }^{12}$ Premda je Hamdija Kreševljaković napisao »Kratki pregled hrvatske knjige u Herceg-Bosni« pruža nekoliko veoma važnih podataka o »Paši duhovnoj« fra Rafe Barišića. Očito je da Kreševljaković nije spuštao pogled na dugi Barišićev uvod jer to djelo svrstava u stvaralačko ozračje fra Matije Divkovića i fra Ivana Bandulavića. ${ }^{13}$ I Kovačić spominje »Pašu duhovnu« kao izvorno djelo biskupa Barišića, iako navodi da je ta molitvena knjiga »iz talijanskog i

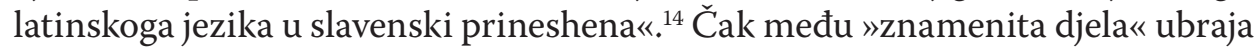
»Pašu duhovnu « fra Robert Jolić. ${ }^{15}$

${ }^{7}$ Kalamut navodi da je pisao stihove: »(...) zatim 'Opovrgnutje Magazina Nikolićeva', pisao je razne pobožne pjesme; prevede 'Mjesec Marijanski', 'Tomu Kempisa', 4 'Razmišljanja kršćanska' za sve dneve u godini« [Marko KALAMUT, Biskup Rafo Barišić. Osmrtnica i životopis, Zagrebački katolički list - crkveno-bogoslovni časopis, 14 (1863) 39, 309-311, 310].

${ }^{8}$ Radoslav GLAVAŠ, O. fra Rafo Barišić, u: Spomenica pedesetgodišnjice Hercegovačke franjevačke redodržave, Mostar, Pacher i Raguž, 1897, 113-127, 118.

9 Julijan JELENIĆ, Kultura i bosanski franjevci, II. sv. (1780.-1878.), Sarajevo, Prva hrvatska tiskara »Karamatić i M. Raguž«, 1915, 434.

${ }^{10}$ Isto, 440-441.

${ }^{11}$ Ivan ALILOVIĆ, Rafo Barišić Stariji, u: Biobibliografija pisaca Bosne i Hercegovine do god. 1918., Zagreb, Ivan Alilović - Kršćanska sadašnjost, 1986, 54-55, 55.

${ }^{12}$ Usp. »Posebno je poznato njegovo djelo Pasha [Paša] duhovna... Rim 1842., koje je bilo traženo i dosta rašireno«; https://www.franjevci.info/povijest-kategorije/pisana-djela (13.06.2018).

${ }^{13}$ »U duhu Divkovića, Bandulavića i drugih starih naših pisaca radili su u ovo doba prva dva biskupa hercegovačka Barišić i Kraljević. Barišić je sastavio molitvenik 'Paša duhovna' (Rim 1842.) poznat u narodu pod imenom 'Biskupova knjiga', i izdao dvanaesto izdanje Bandulovićevih 'Pištola i Evangjelja' « (Hamdija KRESEEVLAKOVIĆ, Kratak pregled hrvatske knjige u Herceg-Bosni od najstarijih vremena do danas, Sarajevo, Prva hrvatska tiskara, 1912, 33).

${ }^{14}$ »Pasha duhovna illiti nacin vjesht slishati svetu missu i pripravitse za ispovid, i sveto priceshtenje : jutarnje, vecernje i drughe mloghe molitve za koje su privezana spasonosna oproshtenja... / iz talijanskog i latinskoga jezika u slavenski prineshena [po Rafi Barišiću]. U Rimu: slovima S. Skuppa od rashirenja virre. 1842., - 439 str.; 18 cm « (Kovačić, nav. dj., 63).

${ }^{15}$ »Napisao je nekoliko znamenitih djela i rasprava na latinskom i hrvatskom jeziku: Conclusiones ex universa philosophia selectae..., Taurini, 1821.; Theses ex theologia selectae..., Taurini, 1822.; Pasha duhovna iliti način (sic!) vjesht slushati svetu misu, Roma, 1842.« [Robert JOLIĆ, Bari- 
Jedino je fra Radoslav Glavaš čitao predgovor »Paše duhovne« [izgleda samo dio] i u monografiji »Život i rad fra Rafe Barišića» iz njega onodobnim suvremenim pravopisom ${ }^{16}$ donosi dva odlomka: jedan o pravopisu, a drugi, znatno veći, iznosi navodno Barišićevo "poimanje jezika«, ali iz uvoda u taj citat, gdje objašnjava razlog citiranja Barišićeva teksta, razvidno je da se njihova shvaćanja uloge jezika sasvim razlikuju:

»Navodimo iz toga uvoda samo njekoliko rieči, koje i današnjemu našemu naraštaju i njegovu silnom nehaju i nemaru mogu biti budnim poticalom na rad za svoj narod i na ljubav prema materinskoj rieči. « ${ }^{17}$

Barišić nasuprot razrađuje tipičnu romantičarsku ideju o neiskvarenosti narodnoga jezika, smatrajući da su obrazovani ljudi iskvarili svoj materinski jezik služeći se u svojim radovima i razgovoru stranim jezikom i veoma čestom uporabom tuđica pa mi sada izvorni jezik trebamo učiti od naroda. ${ }^{18}$ Istom se idejom vodi čitav preporod i na jezičnom i na književnom planu. Veoma je cijenjena narodna književnost i stvara se pravo mnoštvo knjiga narodnih pjesama sa svim vrstama stiha i ritma. Svijest o zapostavljanju hrvatskoga jezika u kulturi jedna je od središnjih ideja preporoda. Sličan problem tematizira kasnije i August Šenoa u »Prijanu Lovri« uvodeći lik obrazovane gospođe koja čita romane na njemačkom. I Barišić se osvrće na to glavno pitanje, koje preporod mora zauvijek odstraniti, te započinje predgovor:

»Koliko je meni poznano, sasma malo nahodi se u slavnom, rodnom i plemenitom slovinskom jeziku duhovni zabava, i bogoljubni molitava, osobito latinskim slovima pritisnuti. Porađa se ovo ubožstvo zašto učeni ljudi, posiduju različite jezike, ko latinski, talianski i njemački, u kojim nalaze svakojaka pomolenja, i pašu za rahniti [tj. hraniti] pobožna srca svoja.« ${ }^{19}$

Iz navedene literature ne doznajemo tko je autor molitvenika »Paša duhovna« (samo se za stihove i za neke molitve može reći da ih je sastavio Barišić), a isto je ili veoma slično stanje i u nenavedenoj literaturi koju tvore uglavnom kratki Barišićevi životopisi i odlikovanja. Slučaj se čini to intrigantnijim što svi autori izrijekom navode da je taj molitvenik nastao u Rimu, gdje je preveden $\mathrm{s}$

šić, fra Rafo (Pavao) (1797.-1863.), u: Leksikon hercegovačkih franjevaca, Mostar, Hercegovačka franjevačka provincija Uznesenja BDM - Franjevačka knjižnica Mostar (niz RECIPE knjiga 9.), 2011, 54-56, 55].

$16 »$ Izpravljamo samo pravopis, a jezik u svem ostavljamo isti « (Radoslav GLAVAŠ, Život i rad fra Rafe Barišića naslovnoga biskupa azotskoga i apoštolskog namjesnika za Bosnu i Hercegovinu, Mostar, Hrvatska dionička tiskara, 1900, 58, bilj. 2.)

${ }^{17}$ Isto, 58.

${ }^{18}$ Usp. »Od naučni ljudi neumjetni uče cvitje i raskošja svoga jezika; a mi, ako ćemo naški izvrsno govoriti, valja da se prikučimo siromaškim kućanicama i pomljivo ćutimo, kako neumjetni govore koji ne poznaju drugoga jezika niti se mješaju š' čeljadma inostranskim« (Rafo BARIŠIĆ, Pasha duhovna illiti nacin vjesht slishati svetu missu i pripravitse za ispovid, i sveto priceshtenje: jutarnje, vecernje i drughe mloghe molitve za koesu privezana spasonosna oproshtenja..., iz talijanskog i latinskoga jezika u slovinski prineshena, Rim, 1842, 7).

${ }^{19}$ Barišić, nav. dj., 5. 
talijanskog i latinskog, ali uvijek fra Rafu Barišića navode kao autora. Svakako postoji opravdan razlog takvom postupanju. U predgovoru sam Barišić piše: »Ama je vrime da se obratim puku momu priprostitom, za koga duhovnu korist i zabavu, složio sam ovu knjižicu. $\aleph^{20}$ Nakon toga biskup izrijekom tvrdi da je molitvena knjiga »Paša duhovna« njegov prijevod:

»Dragi moji krstjani naći ćete u ovoj knjigi svakojaki molitava, koje sam prinio iz drugi jezika za vaš duhovni napredak; a nješto i po meni sastavio (istaknuo P. K.). Imadući pak prigodu pritisnuti slovima Svetoga skupa od raširenja vire, natisko sam, tako da reknem, i nakljukao, gdi sam što mogo, znadući dobro, da u našoj državi manjkaju knjige bogoljubne. $\ll^{21}$

Potom hrabri vjernike da se ne plaše silnog mnoštva navedenih molitava od kojih su neke kontemplativne, a najveći dio molitvenika su detaljna objašnjenja kako se postižu konkretni oprosti; zatim ih potiče da čitaju prema svojim mogućnostima - »već nastojte štiti, koliko morete« (istaknuo P. K.) - ali da to čine pred onima koji još ne znaju čitati - »štijte $i$ prid drugom čeljadim koja ne znadu štit po sebi, $i$ ovako bićete korisni $i$ vama $i$ vašim iskrnjim «. ${ }^{22}$

Posebno preporučuje molitve »za koje su privezana oproštenja sveti Otaca Papi koja su istinita, pomljivo izvađena iz knjige zlatne talijanski pisane, i pritisnute deveti put u Rimu godine 1837.«. ${ }^{23}$ Potom Barišić piše da je $\mathrm{u}$ »Pašu duhovnu « unio nešto stihova jer zna da su njegovom puku drage pjesme i da najviše u njima uživaju. Tu karakteristiku Hercegovaca osobito ističe Bakula u svojim šematizmima. ${ }^{24}$ Riječ je dakle o postojanoj karakteristici Hercegovaca. Barišić navodi:

"Znadem da vam se dopadaju i slade pjesme: radi šta sastavio sam njekoliko za samu vašu zabavu, želeći, da misto popivki neuredni i na razblude probuđujući, ove štijete, koje će užgat ljubav u vama prama Bogu i pričistoj Divici Mariji majki Isusovoj i pobuditi bogoljubna pohotjenja u vašim srcima. ${ }^{25}$

Opće je poznato da se već stoljećima neprestano nastojalo profane pjesme (pjesme $\mathrm{s}$ profanim sadržajima) zamijeniti sakralnim tekstom u pjesmama,

\footnotetext{
${ }^{20}$ Isto, 12-13.

${ }^{21}$ Isto, 13.

${ }^{22}$ Isto.

${ }^{23}$ Isto.

${ }^{24}$ Kad opisuje narav i sposobnost Hercegovaca piše Bakula: »Nadareni su oštroumljem, veseli, neobično vole pjesme i priče« (Petar BAKULA, Hercegovina prije sto godina ili Šematizam fra Petra Bakule, s lat. izv. iz 1867. godine prev. dr. fra Vencel Kosir, Mostar, Hercegovački franjevci, 1970, 26). U drugom šematizmu doslovno ponavlja tu karakteristiku Hercegovaca u odjeljku: »Narav i sposobnost«. Tu pored ostalog navodi: »Nisu proždrljivi, vole popiti. Nadareni su oštroumljem, veseli, neobično vole pjesme i priče« (Petar BAKULA, Topografsko-historijski šematizam Apostolskog vikarijata i Franjevačke misijske kustodije u Hercegovini za godinu Gospodnju 1873., Mostar, Hercegovačka franjevačka provincija Uznesenja BDM - Franjevačka knjižnica Mostar, 2016, 207).

${ }^{25}$ Barišić, nav. dj., 14.
} 
ponekad se zadržavao ritam i napjev profane pjesme. ${ }^{26}$ Barišić je, dakle, autor pjesama što se nalaze u molitveniku »Paša duhovna« i on je obavio izbor molitava koje je preveo, neke s talijanskog, a neke s latinskog, neke biskup, a neke biskupov tajnik, i uvrstili ih u spomenutu molitvenu knjigu. Da je Barišić pisao i stihove jedino je u njegovu životopisu spomenuo Marko Kalamut, ali vrlo neodređeno, »pisao je razne pobožne pjesme «. ${ }^{27}$ Neposredno nakon toga kaže da mu je u prevođenju molitvenika pomagao fra Marko Kalamut, navodeći korektno što je Kalamut preveo te da je njegov prijevod tiskan »malo drugčijim pravopisom «. ${ }^{28}$ Dakle, Kalamut je preveo prvih 130 stranica (17-147), gotovo trećinu knjige.

U molitveniku se nalazi desetak pjesama veoma različite dužine, kompozicije i sadržaja. Prva pjesma je nenaslovljena, složena u kvatrenima, a nalazi se poslije Molitve svetom anđelu stražaninu (str. 156-157). Biskupovi stihovi ne posjeduju neku umjetničku vrijednost jer je, čini se, svu svoju pjesničku snagu istrošio na izgradnji korektne rime i na ispravnost teološkog nauka, koji se daleko brže i lakše pamti kada je »pretočen« u stihove nego kad se nalazi kao tekst. Veoma se to jasno konstatira usporede li se tri strofe pjesme s prethodnom »Molitvom svetom anđelu stražaninu $\aleph^{29}$ ili stihovi:
»O nebeski Božji Anđele
Koji čuvaš mene vele;
Ja sam ozgor pridat tebi,
Da u zloće upo ne bi.
Nut' prosvitli dušu moju,
Nek ispunja volju tvoju:

\footnotetext{
${ }^{26}$ »Žalosno je što se u našoj književnoj historiografiji fra Lovru Šitovića najčešće spominje u negativnom kontekstu, tj. kako je imao opaku namjeru 'istisnuti narodne pjesme' i zamijeniti ih duhovnim « [Pavao KNEZOVIĆ, Šitovićeva poetika usmenog pjesništva u posveti Pisne od pakla, u: Pavao Knezović (ur.), Zbornik o Lovri Šitoviću, Zagreb, Hrvatski studiji Sveučilišta u Zagrebu, 2009, 205-215, 205]. »Slušaoče, poljubljeni brate, (...) ti pivaš i slušaš pisme od Kraljevića Marka, Muse Arbanasa, Relje Bošnjanina od vojske (...) lipote divojke, od rujnoga vina i od ostalih brezkorisnih pisamih...« (isto, 207-208). »U posveti svoje poeme Pisna od pakla (...) Šitović ukazuje na pogibeljne motive koji su se obrađivale u usmenoj poeziji« (isto, 214).

${ }^{27}$ Kalamut, nav. dj., 310.

${ }^{28} »$ Pomogo me je, ne samo u pripisivanju i popravljanju ovoga, kakva, takog rukodilja O. P. fra Marko Kalamut štioc bogoslovice i moj vridni otajnik, dali i u prinešenju i sastavljanju; buduć viši dio molitava za slišati svetu misu prinio, kako i druge molitve prija i posli ispovidi i pričešćenja, koje se nahode u ovoj knjigi malo drugačijim pravopisom stavljene« (Barišić, nav. dj., $14)$.

${ }^{29} » \mathrm{O}$ Anđele sveti, plemeniti poglavaru, virni čuvaocu, i branitelju moj, ja te pozdravljam slatkim srcem dobroga moga Isusa, koji te je odredio meni za vođu, i druga. Koliko si me zadužio, budući toliko godina, da samnom virno pribivaš, upravljaš, svituješ, i nadanjuješ, da činim ona koja su za spasenje duše moje, i korist moga tila? Danas za sve mene priporučujem dobroti tvojoj virni Anđele, kako ću moći s' tobom, i po tebi, pridobiti neprijatelja, hudoga i opakoga zlotvora duše moje, djavla paklenoga, svit, i zle požude moje, ter da do posljednjega časa života moga uzdržim u meni milost svetu Božiju, i s' tobom zaedan fale uzdajem vičnjem Bogu, u vike vikova. Amen« (isto, 155-156).
} 
Nek se od tebe ne odkučim,

Da s' od Boga ne odluči.

Čuvaj, vladaj i upravljaj,

I nigda me ne ostavljaj;

Tad ću vazda srićan biti

I u raju vik živiti. Amen. $\aleph^{30}$

Drugu kratku Pjesmu (takav ima naslov) tvore četiri katrene i čini se da su to Barišićevi najslabiji stihovi. ${ }^{31}$ Treću se teško može nazvati pjesmom, jer niti ima naslova, niti njenih šest stihova ima neku čvršću strukturu, a ni stihovi (dva deseterca, jedan jedanaesterac i na kraju tri osmerca) nisu povezani rimom. ${ }^{32}$ Pored tih kraćih pjesama »Paša duhovna« donosi jednu neobičnu Pjesmu koja je dvoglasna. ${ }^{33}$

Zasebnu cjelinu tvore Barišićeve znatno duže pjesme otisnute jedna za drugom počev sa 168. stranicom pa sve do 192. stranice, donosi također tri znatno duže pjesme među kojima se nalazi i Pjesma koja se pjeva na Božić, ${ }^{34}$ a nakon nje slijedi pjesma posvećena Blaženoj Djevici Mariji: Pisma Blaženoj Divici Mariji za isprosit njezino utočište. ${ }^{35}$ Prva je Pjesma za pozdraviti sakramenat na otaru (ima 126 stihova), a druga Pisma duhovna Srcu Isusovu koju tvore 182 stiha, a najduža je Pisma Blaženoj Divici Mariji za isprosit njezino utočište (ima 294 stiha). Najvjerojatnije su upravo ovi stihovi presudili da se autorstvo molitvene knjige »Paša duhovna« pripisuje fra Rafi Barišiću. Drugi je, možda i pouzdaniji razlog, sam autoritet koji je uživao biskup Barišić kod svih Mostaraca te ugled koji je imao u Beču, Istanbulu i Rimu. ${ }^{36}$ Potom uobičajeno

\footnotetext{
${ }^{30}$ Isto, $156-157$.

31 »O divica sviu slavna,| Svrhu zvizda uzvišena,| Čedo, koje tebe stvori| Sisućom ga rahniš| Tužna Eva što porazi,| Ti povraćaš s' plodom svetim,| Da plačući u raj dođu,| Nebesa jim ti otvaraš.| Ti s' visokog kralja vrata,| I polača svitlo sjajna:| Život dati po divici,| Otkupljeno ljudstvo slavi,| Teb Isuse budi slava,| Koj si rođen od divice,| S' Ocem, a ims' Duhom svetim,| U sve vike vikova. Amen| « (isto, 370-371).

${ }^{32}$ Prva dva stiha su deseterci i imaju rimu (»Nek dopusti milost odpuštenja | Prija dana strašnog rasuđenja«), potom slijedi stih od 11 slogova koji se uopće ne doživljava kao dio pjesme: »Od jaraca (grišnika) nek me dili«, zatim slijede 3 osmerca: »Mist' u ovcam i podili | I proklete kad porazi | Nek me s' dobrim primiv pazi« (isto, 201).

${ }_{33}$ „Pjesma | Redak. Sva si lipa o Marijo.| Odgovor. Sva si lipa o Marijo.| Red. I oskvrnjenje istočno nije u tebi.| Odg. I oskvrnjenje istočno nije u tebi.| Red. Ti si slava Jeruzolimska.| Odg. Ti si veselje izraelsko.| Red. Ti si dika puka našega.| Odg. Ti si odvitnica grišnika.| Red. O Mario.| Odg. O Mario.| Red. Divico prirazborna.| Odg. Majko pridobrostiva. Red. Moli za nas.| Odg. Uteci se za nas kod gospodina Isukarsta.| Red. U začetju tvomu, Divico, neoskvrnjena bila jesi.| Odg. Moli za nas Oca čijeg si Sina porodila« (isto, 340-341).

${ }^{34}$ Isto, $179-182$.

${ }^{35}$ Isto, 182-192.

${ }^{36}$ Fra Petar Bakula u šematizmu za 1873. godinu navodi: »Radi baš neobične slave spomenuta preminula biskupa, Francuska mu je 1853. podijelila čast začasnog predsjednika Pobožnog afričkog instituta. Turski car ga je odlikovao godine 1859. viteškim redom i napokon 1861. austrijski car redom željezne krune II. reda. On je prvi apostolski vikar u našoj Turskoj koga su resila javna odličja vladara« (Bakula, Topografsko-historijski šematizam..., 214).
} 
"povjerenje« starijoj literaturi te su iz nje prenošeni i pogrešni podaci; potom raritetnost primjeraka »Paše duhovne«, što nekim biografima nije omogućilo da to biskupovo djelo svrstaju u prijevode. Tek na 217. stranici biskup progovara o prevedenim molitvama iz talijanske knjige, izdane deveti put, a on je tada $u$ Rimu imao izdanje iz 1837. godine. Barišić navodi: »Molitve izvađene iz knjige, talijanski pisane, pritisnute u Rimu godine 1837. kojim su pristavljena različita oproštenja od Sveti Otaca Papa, kako ćeš naučit slideći nadalke.« Nakon toda nalazi se nekoliko molitava uz koje su povezani raznorazni oprosti. Barišić najveću pažnju posvećuje biranju molitava i molitvice s detaljnim objašnjenjima kako se uz njih postižu oproštenja (revno navodi za koliko dana ili zavazda), a potom detaljno objašnjava postizanje rečenog oproštenja: »Istomačenje oproštenja«. Većinu »Paše duhovne«, pored spomenutih »istomačenja oproštenja«, popunio je raznim krunicama (npr. »Krunica Isusova«, str. 241-249); a tu je i »Kratko uvižbanje za učiniti put križa«, str. 253-270; »Način govoriti sveto rožarije«, str. 299-308; zatim navodi pet devetnica, redovito s »istumačenjima oproštenja« str. 337-390 itd. Kad je dobio dopuštenje da »Pašu duhovnu« može tiskati Propagandinim slovima (tj. besplatno), Barišić je od 217. str. pa sve do zadnje korice, odnosno do »Kazala«, 428. str. »Pašu duhovnu« prenatrpao odnosno (»nakljukao - kako on veli) raznim molitvama s detaljnim istumačenjima koliki se i kakav dobiva oprost.

I pored navođenja da je »Paša duhovna« nastala iz raznih talijanskih i latinskih knjižica koje su fra Marko Kalamut i fra Rafo Barišić preveli na hrvatski, ipak svekolika naša biografska literatura (od fra Ivana Frane Jukića do Hrvatskog franjevačkog biografskog leksikona) kao autora knjige navode fra Rafu Barišića. Također taj se molitvenik redovito nalazi naveden među njegovim izvornim djelima, obično na prvom mjestu. Smatram da su tomu poimanju ponajviše pridonijeli stihovi koji su otisnuti oko polovice molitvenika i najvjerojatnije ljudi, koji su znali čitati, štili su naglas upravo njih. Taj dio molitvenika (str. 168193) i neke molitve doista jesu izvorno Barišićevo djelo. ${ }^{37}$ Budući da se stihovi najbrže i najduže pamte, ljudi koji su slušali jednostavno su čitav molitvenik nazivali »Bikupovom knjigom« ili oni malo učeniji »Pašom duhovnom«. Pisci biskupova životopisa pouzdano nisu čitalj predgovor »Paše duhovne« u kojem jasno piše što je preveo fra Marko Kalamut i kojim se pravopisom služio, ${ }^{38}$ a što fra Rafo Barišić. Oni redovito »gledaju« samo naslovnicu i s nje prenose podatke (odnosno dio podataka ${ }^{39}$ ) ili ih preuzimaju iz postojeće literature $u$

\footnotetext{
${ }^{37}$ »Dragi moji krstjani, naći ćete u ovoj knjigi svakojaki molitava, koje sam prinio iz drugi jezika za vaš duhovni napredak; a nješto i po meni sastavio « (Barišić, nav. dj., 13).

$38 \gg$ Pomogao me je, ne samo u pripisivanju, i popravljenju, ovoga, kakva, takog rukodilja o. p. fra Marko Kalamut štioc bogoslovice, i moj vridni otajnik, dali i u prinešenju i sastavljanju: buduć viši dio moitava za slišati svetu misu prinio, kako i druge molitve prija i posli ispovidi i pričešćenja, koje se nahode u ovoj knjigi malo drugačim pravopisom stavljene« (isto, 14).

${ }^{39}$ Naslovnica ove knjige donosi sljedeće podatke: »Paša duhovna | iliti način vješt | slišati svetu misu | i pripravit se | za ispovid, i sveto pričeštenje | jutarnje, večernje, i druge mloge | molitve
} 
kojoj su nastali na isti ili sličan način. Naslovnica ne navodi svoga autora. Isto tako ne spominju se pjesme koje je sastavio biskup. Najjednostavnije je čitavu »Pašu duhovnu« bilo pripisati fra Rafi Barišiću, a da se ne navodi razlog za taj postupak. Pored toga što sam biskup u predgovoru navodi da je sakupio nekoliko knjižica na talijanskom i latinskom u kojima su bile tiskane molitve uz čije su moljenje pojedine pape dale određen broj dana oprosta ili »zavazda«, a najviše je uzeo iz neke zlatne knjige koja je 1837. godine deveti put tiskana u Rimu. Pored toga, znajući da njegov puk voli poeziju, i on se okušao i sastavio je desetak, što kraćih što dužih pjesama (oko 640 stihova), uglavnom u osmercima s veoma korektnom rimom. Budući da su oni koji su znali čitati to morali raditi naglas, drugi su ih slušali i tako učili. Čini se da su upravo ovi stihovi bili presudni što je kompletno djelo redovito navođeno kao Barišićevo.

| za koje su privezana spasonosna oproštenja | od sveti otaca papi | pet devetnica | za pripravljenje svetkovinam | Blažene Divice Marie; | iz talianskog i latinskoga | jezika u Slovinski prinešena na zabavu priprostitog puka | Bosanskoga. | u Rimu, | Slovima S. Skupa od Raširenja Vire. | 1842.« 


\section{Knezović Pavao* \\ Authorship of the Prayer Paša duhovna /Spiritual Pasture/ \\ Summary}

While in Rome due to the dispute he had with the authority of the province Bosnia Argentum, bishop friar Rafo Barišić had collected a few booklets in Italian and Latin (primarily, he collected booklets containing prayers for which different popes were giving forgiveness) and with the assistance of his secretary friar Marko Kalamut compiled a booklet of prayers entitled Spiritual Pasture (Rome, 1842), which was popularly referred to as Bishop's book. In the foreword (p 5-15) Barišić elaborated upon the entire programme of the Illyrian Movement. However, this paper will propose the solid reasoning on why Spiritual Pasture has been considered one of Barišićs main works by many biographers, even though some of them have referred to it as a translation. Nevertheless, only a dozen shorter and longer poems, approximately 640 verses, were composed by friar Rafo Barišić. Having in mind that his congregation/people liked poems, he made an attempt to create sacral poetry. Thereto, it is worth noting that any literate person had to read aloud so that illiterate people could learn things from the Bishop's book. It is definitely more appropriate to recite verses than prose. Barišić was a weak poet and it seems that he put all his strength into making up rhymes (which are perfect) and delivering theologically exact content. None the less, it should be pointed out that Barišić's octameter poems are comprised of numerous solid couplets.

Key words: friar Rafo Barišić, Spiritual Pasture, Barišić's poems, perfect rhyme and theological exactitude.

(na engl. prev. Alica i Zrinka Knezović)

\footnotetext{
* Pavao Knezović, PhD, Full Prof., Centar for Croatian Studies, University of Zagreb; Address: Borongajska cesta 83d, HR-10000 Zagreb, Croatia; E-mail: pknezovic@gmail.com.
} 